\title{
Saccharothrix yanglingensis Strain Hhs.015 Is a Promising Biocontrol Agent on Apple Valsa Canker
}

Zhengpeng Li, Xiaoning Gao, Zhensheng Kang, and Lili Huang, State Key Laboratory of Crop Stress Biology for Arid Areas and College of Plant Protection, Northwest A\&F University, Yangling 712100, PR China; Dongying Fan and Xia Yan, College of Life Sciences, Northwest A\&F University; and Zhensheng Kang, China-Australia Joint Research Centre for Abiotic and Biotic Stress Management, Northwest A\&F University

\begin{abstract}
Li, Z., Gao, X., Fan, D., Yan, X., Kang, Z., and Huang, L. 2016. Saccharothrix yanglingensis strain Hhs.015 is a promising biocontrol agent on apple Valsa canker. Plant Dis. 100:510-514.

Apple Valsa canker (AVC), caused by Valsa mali, results in a serious and persistent disease problem for apple production in China and is difficult to control by chemical and agricultural measures. In this study, we determined the inhibitory effects of an endophytic actinomycete Saccharothrix yanglingensis strain Hhs. 015 on V. mali under laboratory and the field conditions. Fermentation broth (FB) of Hhs.015 significantly inhibited conidial germination and mycelial growth, causing malformed and dysfunctional fungal structures. Detached apple (Malus domestica 'Fuji') twigs smeared with

FB before $V$. mali inoculation significantly reduced lesion development, especially sporulation. In the orchard trials conducted from 2010 to 2013, trunks and branches smeared with FB three times significantly reduced the number of new lesions. In addition, wounds after lesion surgery coated with FB also enhanced callus formation and significantly improved the cure rate. The results showed that $S$. yanglingensis Hhs. 015 is effective against AVC in orchards. Thus, $S$. yanglingensis $\mathrm{Hhs} .015$ can be further developed as an effective biocontrol agent for more sustainable management of AVC.
\end{abstract}

Apple Valsa canker (AVC), caused by Valsa mali, has been an destructive disease of apple trees (Malus spp.) in eastern Asia (Abe et al. 2007; Lee et al. 2006), especially in China, where tree losses can reach 100\% (Chen et al. 1987; Li et al. 2013; Wang et al. 2005; Wang et al. 2014). Repeated outbreaks of AVC seriously reduce tree productivity as cankers cause dieback on twigs, scaffold limbs, and trunks (Ke et al. 2013; Wang et al. 1986). Because the pathogen penetrates extensively into the host phloem and xylem, Valsa canker is difficult to control through chemical treatments and is inaccessible to conventional fungicide treatments (Zhang et al. 2015). Traditional control measures such as canker surgery and pruning infected limbs (Wang et al. 1986) are inadequate because they inflict further damage on the trees. All commercial apple cultivars are susceptible to the disease (Abe et al. 2010; Bessho et al. 1994; Liu et al. 2011). Therefore, a new, safer, and more effective measure for control of AVC is needed.

For sustainable agriculture, biological control appears to offer several advantages. Numerous studies have indicated that actinobacteria are capable of producing an array of secondary metabolites exhibiting a wide variety of biological activities, such as antibiotics, plant growth promoters, and enzymes, and may contribute to their host plants by promoting growth and enhancing tolerance to environmental stresses (Qin et al. 2011). However, research on biological control application as a strategy against cankers on fruit trees is in its infancy (Ren et al. 2013; Zhang et al. 2015).

The endophytic actinomycete strain Hhs.015, isolated from cucumber roots and identified as Saccharothrix yanglingensis (Yan et al. 2012), has been shown to inhibit a wide range of microorganisms (Gao et al. 2009; Wang et al. 2010; Yan et al. 2012; Yao et al. 2007). The stability of its active metabolites has been evaluated under various

Corresponding author: L. Huang; E-mail: huanglili@nwsuaf.edu.cn

*The $\boldsymbol{e}$-Xtra logo stands for "electronic extra" and indicates that one supplementary figure is published online.

Accepted for publication 3 September 2015.

http://dx.doi.org/10.1094/PDIS-02-15-0190-RE

(C) 2016 The American Phytopathological Society temperature, $\mathrm{pH}$, and ultraviolet radiation conditions (Yan et al. 2012). Given this potential for application, we focused the present study on assessing the effectiveness of S. yanglingensis Hhs.015 for biocontrol of AVC under laboratory and field conditions.

\section{Materials and Methods}

Culture of $\boldsymbol{V}$. mali and $\boldsymbol{S}$. yanglingensis strains. V. mali strain 03-8 (Wang et al. 2011) was cultured on potato dextrose agar (PDA) and stored at $4^{\circ} \mathrm{C}$. S. yanglingensis strain Hhs. 015 was cultured on Gause's number 1 synthetic agar medium stored at $4^{\circ} \mathrm{C}$. For long-term storage, the strains were preserved in $20 \%$ glycerol at $-80^{\circ} \mathrm{C}$.

Preparation of fermentation broth. Strain Hhs. 015 was maintained on Gause's number 1 synthetic agar medium for 4 days and activated as described by Wang et al. (2010). A single colony was transferred into a 250-ml Erlenmeyer flask containing $90 \mathrm{ml}$ of fermentation medium consisting of $15 \mathrm{~g}$ of apple pomace, $4 \mathrm{~g}$ of rapeseed meal, $0.1 \mathrm{~g}$ of $\mathrm{KH}_{2} \mathrm{PO}_{4}$, and $0.6 \mathrm{~g}$ of $\mathrm{MgSO}_{4} \cdot 7 \mathrm{H}_{2} \mathrm{O}$ in 1 liter of distilled water. The flask was shaken at $100 \mathrm{rpm}$ for 4 days at $25^{\circ} \mathrm{C}$, and the fermentation broth (FB) was collected and stored at $4{ }^{\circ} \mathrm{C}$ until use.

Conidial germination assays. Fresh conidia ( 150 conidia/treatment $)$ of $V$. mali strain 03-8 were spread uniformly on the surface of PDA containing FB with various dilutions (0-, 10-, 50-, 100-, 300-, 500-, and 1,000 -fold). Water was used as a negative control. The experiment was performed with three replications and repeated three times. The percentage of conidial germination was recorded by light microscopy after incubation at $25^{\circ} \mathrm{C}$ for $24 \mathrm{~h}$.

Mycelial growth assays. V. mali strain 03-8 was cultured on PDA for 3 days at $25^{\circ} \mathrm{C}$, and a mycelial disc $(5 \mathrm{~mm}$ in diameter) was then transferred into a 250-ml Erlenmeyer flask containing $100 \mathrm{ml}$ of potato dextrose liquid medium with different FB dilutions (0-, 10-, 50-, 100-, 300-, 500-, and 1,000-fold). Sterile water was used as a control. The experiment was conducted with three replications and repeated three times. The flask was shaken at $100 \mathrm{rpm}$ for 3 days at $25^{\circ} \mathrm{C}$, and the mycelial dry weight was measured.

Light and transmission electron microscopy analyses. The effectiveness of the $S$. yanglingensis Hhs.015 treatment on mycelial growth was determined by light and transmission electron microscopy, as described by Huang et al. (2001). Four discs containing mycelia of $V$. mali isolate 03-8 (5 $\mathrm{mm}$ in diameter) were placed around the edge of a petri dish containing PDA, and a disc ( $5 \mathrm{~mm}$ in diameter) containing 
strain Hhs.015 was placed at the center of the petri dish. The dishes were incubated at $25^{\circ} \mathrm{C}$ for 4 days.

Detached twig assays. The effectiveness of S. yanglingensis Hhs.015 was tested on detached twigs in the laboratory. Healthy twigs from 'Fuji' apple were treated as previously described (Wei et al. 2010). The Hhs.015 FB was uniformly daubed onto the surface of each segment. After $15 \mathrm{~min}$ of air drying, mycelial blocks $(5 \mathrm{~mm}$ in diameter) of V. mali 03-8 and agar blocks (control) were inoculated onto the wound of each segment. The treated twigs were maintained in a moisture-controlled chamber at $25^{\circ} \mathrm{C}$. Water was used as a negative control. The size of lesions and the number of pycnidia were recorded 3, 5, 7, 10, and 12 days after the $V$. mali inoculation. The experiment was performed with nine replications and repeated three times.

Preventive effects of $S$. yanglingensis Hhs.015 on AVC in orchards. The preventive effect of $S$. yanglingensis Hhs. 015 on AVC was evaluated under field conditions in randomized block design experiments in Pucheng County (N35 $08^{\prime} 24.20^{\prime \prime}$, E109 $33^{\prime} 6.28^{\prime \prime}$ ) and Wuquan

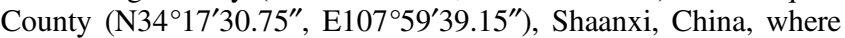
AVC incidence was approximately $60 \%$. In both orchards, 15 -year old Fuji apple (Malus domestica), susceptible to V. mali, was grown. The experiments were conducted in April, June, September, and December 2010 . The trunk ( $2 \mathrm{~m}$ high $)$ and large branches $(0.4 \mathrm{~m}$ long) of an apple tree were smeared uniformly with $S$. yanglingensis Hhs.015 FB fivefold dilution (1 liter/tree) and, 15 and 30 days later, smeared again. The treatment was replicated in three plots (including 30 apple trees each) and repeated in the same area in June 2011, 2012, and 2013. Plots treated with sterile water were used as controls. Lesions with a swollen, water-soaked, soft appearance were considered new after every data collection. The total number of new lesions after smearing was recorded every 3 months until the next June, which is a peak of lesion formation.

Effects of $S$. yanglingensis Hhs.015 on lesion healing of AVC in orchards. The healing effect of $S$. yanglingensis Hhs. 015 was investigated in the same area in Pucheng County in April 2010. New lesions of approximately 5 to $10 \mathrm{~cm}$ in diameter were selected. The lesions were scraped smoothly up to the xylems with a sterile knife. Hhs.015 FB was coated uniformly on the postoperative lesion (Supplementary Fig. S1) and coated again 15 and 30 days later. The treatment was replicated 21 times and repeated in the same region in April

Table 1. Inhibition effects of Saccharothrix yanglingensis Hhs.015 on conidial germination and mycelial growth of Valsa mali ${ }^{\mathrm{w}}$

\begin{tabular}{|c|c|c|c|c|c|c|c|c|}
\hline Dilution (fold) ${ }^{x}$ & Control & $\mathbf{0}$ & 10 & 50 & 100 & 300 & 500 & 1,000 \\
\hline Germination rate $(\%)^{\mathrm{y}}$ & $98.2 \pm 4.7 \mathrm{a}$ & $0.0 \pm 0.0 \mathrm{f}$ & $0.0 \pm 0.0 \mathrm{f}$ & $0.7 \pm 0.1 \mathrm{e}$ & $3.7 \pm 0.4 \mathrm{~d}$ & $28.6 \pm 1.1 \mathrm{c}$ & $52.8 \pm 2.2 \mathrm{~b}$ & $97.4 \pm 4.2 \mathrm{a}$ \\
\hline Mycelial dry weight $(\mathrm{mg})^{\mathrm{z}}$ & $285 \pm 5.2 \mathrm{a}$ & $9.8 \pm 0.4 \mathrm{~h}$ & $15.5 \pm 0.5 \mathrm{~g}$ & $27.0 \pm 0.4 \mathrm{f}$ & $48.0 \pm 1.2 \mathrm{e}$ & $132 \pm 2.6 \mathrm{~d}$ & $155.0 \pm 2.1 \mathrm{c}$ & $182 \pm 3.6 b$ \\
\hline
\end{tabular}

${ }^{w}$ Values are the mean \pm standard error of three replications and repeated three times. Different lowercase letters in the same row indicate significant difference $(P=0.05)$ between different dilutions according to least significant difference test.

$\times$ Various dilutions of $S$. yanglingensis Hhs.015 fermentation broth (FB) and sterile water were used as treatments and control, respectively.

y Germination rate (more than 150 conidia in five visual fields under a light microscope) was examined after conidia of $V$. mali isolate $03-8$ were treated with $S$. yanglingensis Hhs. 015 for $24 \mathrm{~h}$. The experiment was conducted three times with three replicates.

${ }^{\mathrm{z}}$ Mycelium was treated with different FB dilution for 3 days and dried in the $35^{\circ} \mathrm{C}$ dryer for $48 \mathrm{~h}$. Data were the mean of nine replicates with three repeated plots
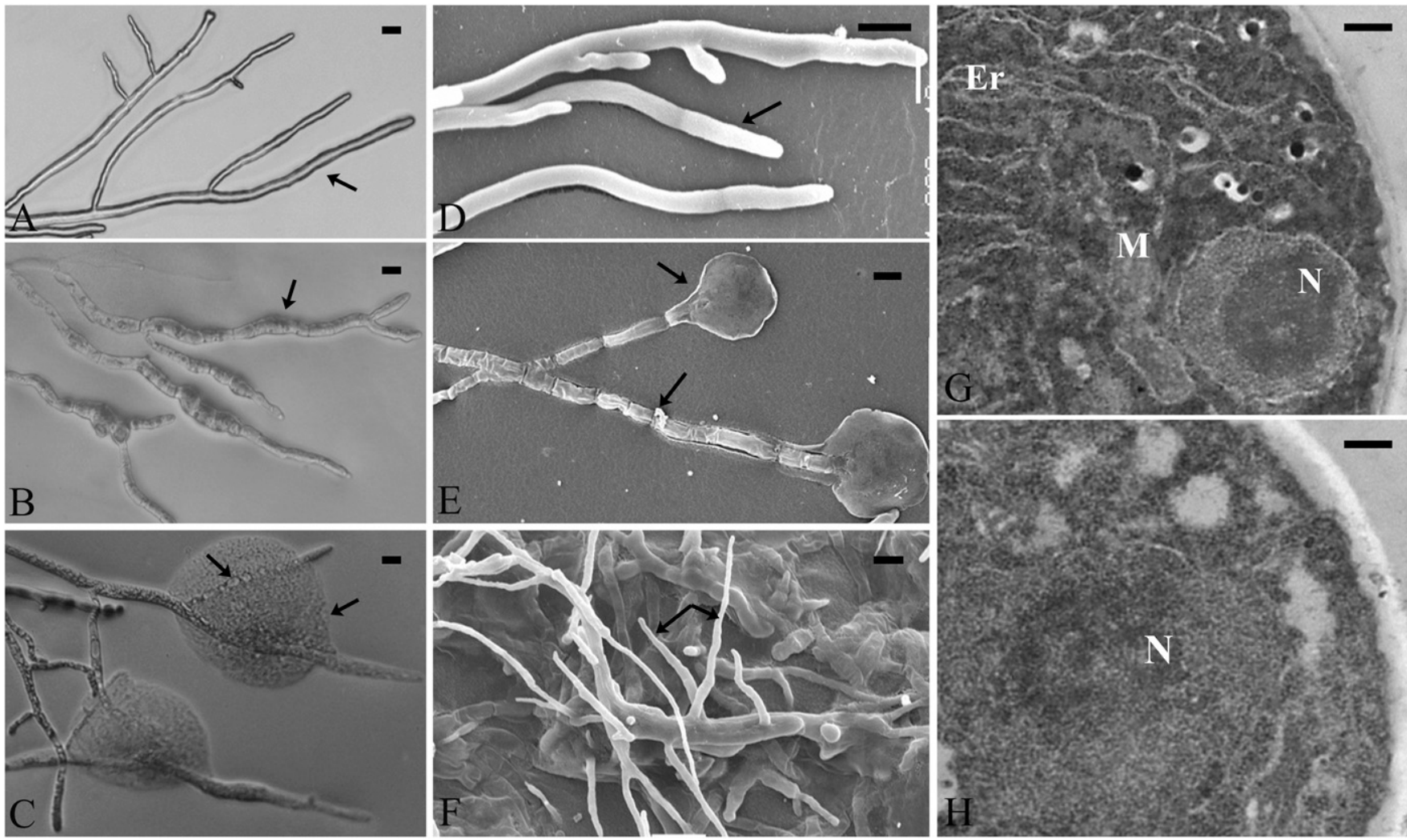

Fig. 1. Micrographs of Valsa mali mycelia treated with Saccharothrix yanglingensis Hhs. 015 fermentation broth for 3 days. Hyphae observed by light microscope, bar $=10 \mu \mathrm{m}$ : A, Normal fungal hyphae. B, Malformed hyphae. C, Mycelia with protoplasm extravasation. Hyphae observed by scanning electron microscope, bar $=10 \mu \mathrm{m}$ : D, Normal fungal hyphae. E, Top of treated mycelia with protoplasm extravasation. F, Treated mycelia with branches. Cross section of treated hyphae observed by transmission electron microscope, bar $=500 \mathrm{~nm}$ : G, Normal fungal hyphae exhibiting integrated and well-organized cell component. H, Treated fungal hyphae showing disintegrated and disordered cell component. $\mathrm{Nm}=$ nuclear membrane, $\mathrm{M}=$ mitochondria, and $\mathrm{ER}=$ endoplasmic reticulum. 
2011 and 2013. Wounds smeared with sterile water were used as control. Healed lesions were defined as lesions without recurrence and with callus. After 2, 6, 9, and 12 months, the number of cured lesions and the width of callus were recorded, and the cure rate was calculated.

Statistical analyses. A combined analysis of variance of the data were conducted using the SAS software package (SAS Institute, Cary, NC). Means of inhibition ratio were compared among dilutions using the least significant difference at $P=0.05$ and means between the control and Hhs.015 were compared using a $t$ test $(P=0.05)$.

\section{Results}

Inhibitory effect of $S$. yanglingensis Hhs.015 on $V$. mali conidial germination. Treatment with different dilutions FB for $24 \mathrm{~h}$ exhibited different conidial germination rates (Table 1). However,
A

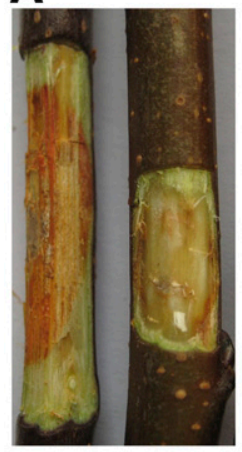

Control Sy Hhs.015

$3 \mathrm{~d}$

$1 \mathrm{~cm}$

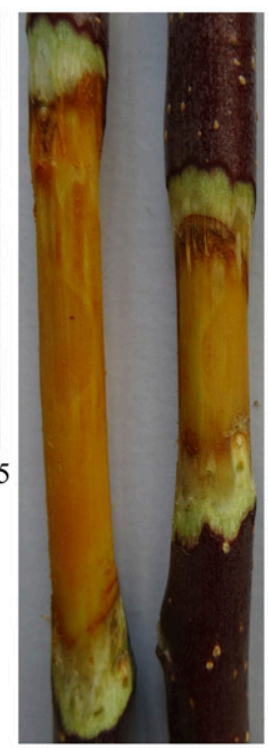

Control Sy Hhs.015

$5 \mathrm{~d}$

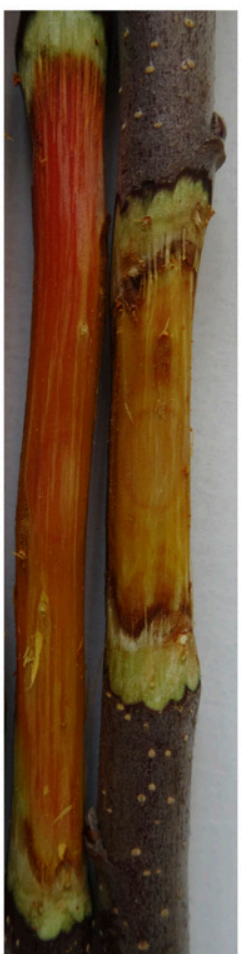

Control Sy Hhs.015

$10 \mathrm{~d}$
B

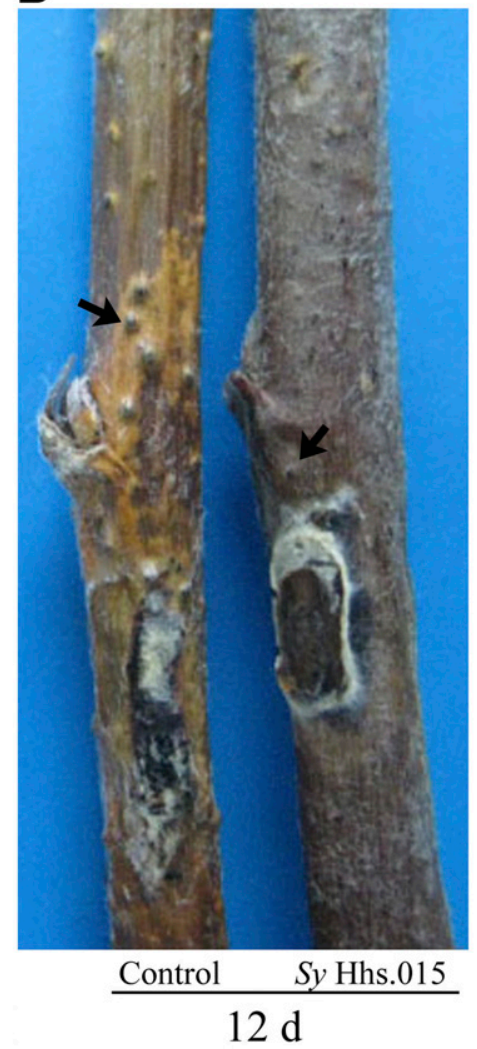

Fig. 2. Saccharothrix yanglingensis Hhs.015 reduced apple Valsa canker lesion development and pycnidial formation. A, Lesion development on twigs after treatments. B, Pycnidial formation (arrows) on lesions.

A

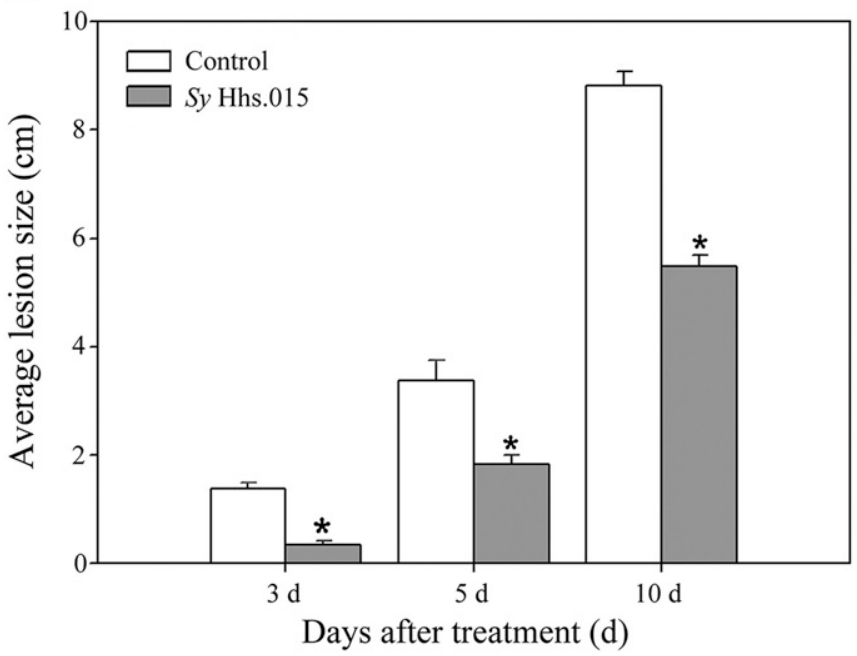

B

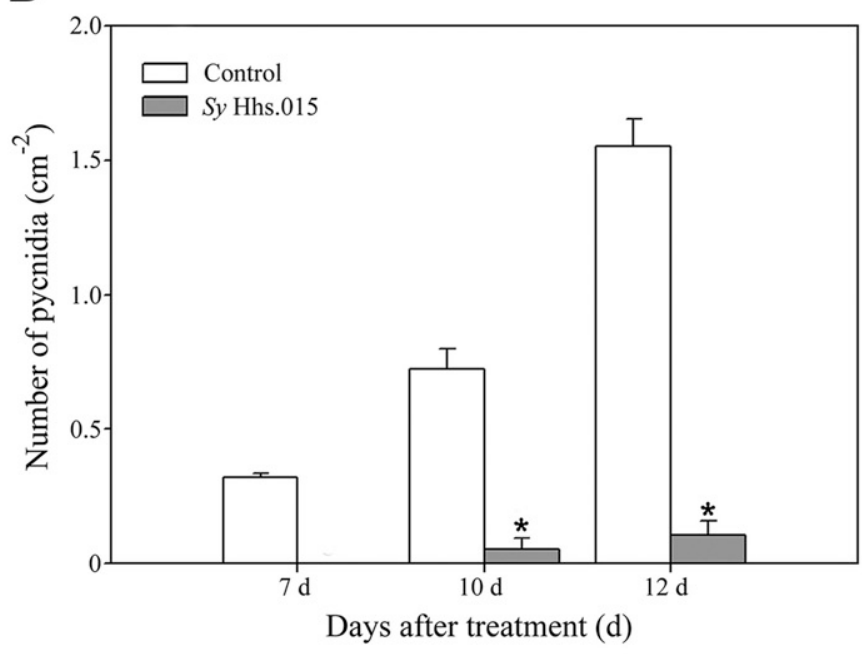

Fig. 3. Preventive effects of the Saccharothrix yanglingensis strain Hhs.015 on apple Valsa canker A, lesion development and B, pycnidial formation under laboratory conditions. Data are means of lesion size or number of pycnidia measured at 3, 57,10, or 12 days after the treatment. Twigs treated with sterile water were used as the control. The experiment was performed with nine replications and repeated three times. Asterisks represent significant difference between control and treatment $(P=0.05)$. Vertical bars indicate standard deviations. 
treatment with $\mathrm{FB}$ at 10 - and 50-fold dilutions almost completely inhibited conidial germination. Furthermore, FB still retained a significant inhibitory activity (about 50\%) even at a 500-fold dilution. Thus, $S$. yanglingensis Hhs.015 exhibits a strong antifungal activity that

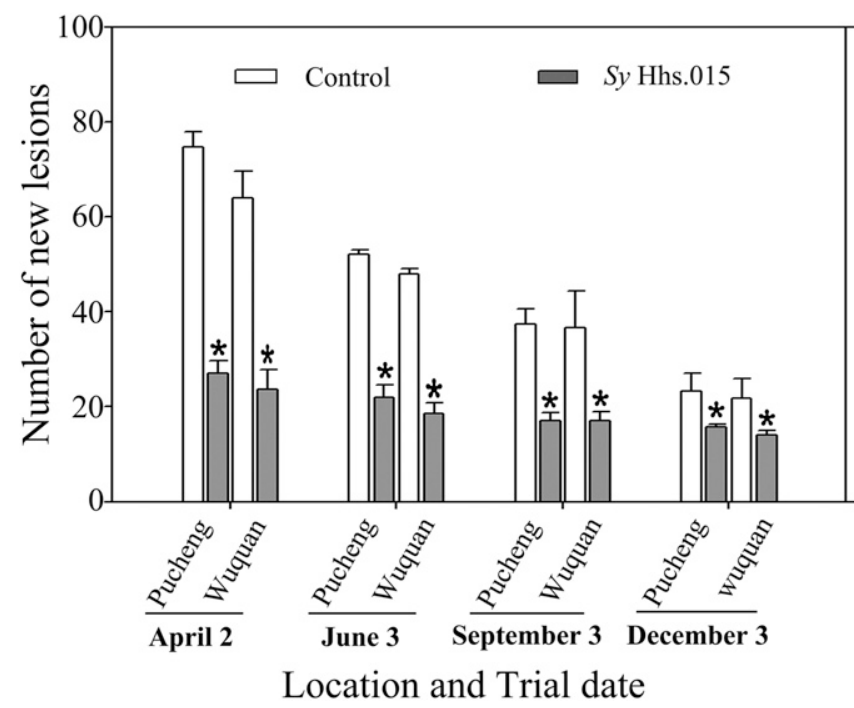

Fig. 4. Preventive effects of Saccharothrix yanglingensis Hhs. 015 on apple Valsa canker in orchards in different seasons in 2010. Fivefold dilution of Hhs.015 fermentation broth and sterile water were used as treatment and control, respectively. Data were the mean of the sum of new lesions recorded every 3 months until April 2011 in a plot with 30 trees in Pucheng and Wuquan Counties, respectively. Asterisks indicate significant differences between control and treatment $(P=0.05)$. Vertical bars indicate standard deviations.

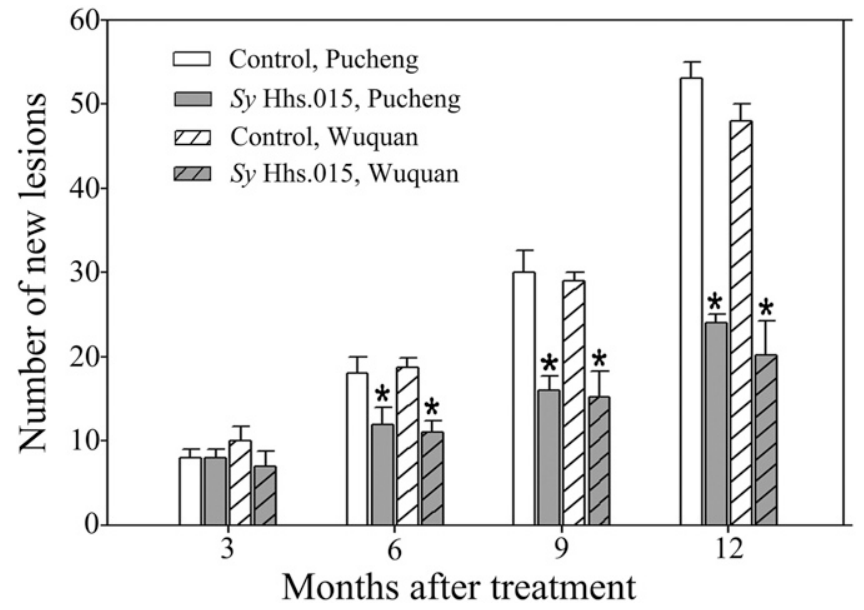

Fig. 5. Total number of new lesions 3 to 12 months after treatment. Fivefold dilution of Saccharothrix yanglingensis Hhs.015 fermentation broth and sterile water were used as treatment and control, respectively. Data are the total number of new lesions 3 to 12 months after treatment in each plot with 30 apple trees in Pucheng and Wuquan Counties. Asterisks indicate significant differences between control and treatment $(P=0.05)$. Vertical bars indicate standard deviations. probably derives from active substances produced by the $S$. yanglingensis strain.

Inhibitory effect of $S$. yanglingensis Hhs.015 on $V$. mali mycelial growth. The treatment with FB (0-, 10-, and 50-fold dilutions) inhibited mycelial growth by more than $90 \%$ (Table 1). Moreover, FB still retained a significant inhibitory activity (about $36 \%$ ) even after a 1,000-fold dilution. The treatment also induced malformation, protoplasm releases, and branches (Fig. 1B, C, E, and F) compared with the normal hypha (Fig. 1A and D). Under a transmission electron-microscope, the structure of the nontreated $V$. mali hyphae cells remained intact, their cellular components appeared arranged in order, and the nucleus was clearly visible (Fig. 1G). In contrast, the organelles (principally mitochondria and endoplasmic reticulum) and cytoplasm in many treated $V$. mali hyphae cells were irregular and degenerated (Fig. 1H), and the nuclear membrane appeared disintegrated (Fig. 1H). Thus, Hhs. 015 exhibited strong inhibitory activity against $V$. mali mycelial growth.

Effect of $S$. yanglingensis strain Hhs.015 on lesion development on detached twigs. FB significantly inhibited lesion expansion and pycnidial production on twigs (Fig. 2). The lesion expansion rate was reduced by $50 \%$ after treatment for 10 days (Fig. 3A). The treatment also delayed pycnidial production by 3 days (Fig. 3B). In addition, the treatment led to a significant decrease in the density of pycnidia formed on the surface of lesions (Fig. 2B). The lesions on the treated twigs produced $0.12 \mathrm{pycnidia} / \mathrm{cm}^{2}$, whereas those of the nontreated control produced 1.56 pycnidia $/ \mathrm{cm}^{2}$ after treatment for 12 days (Fig. 3B). The treatment with FB effectively reduced hyphal growth in the tissues and conidial production on the lesion and, thereby, reduced the inoculum density of the pathogen.

Preventive effects of $S$. yanglingensis Hhs.015 on AVC in orchards. Treatment with FB in 2010 significantly reduced the number of new lesions, providing a consistent control efficacy of approximately $60 \%$ in April and June particularly (Fig. 4). The June 2011 trial showed that the treatment with FB markedly attenuated the lesion formation $3,6,9$, and 12 months after treatment, until the next April, which is a peak time period for conidia release and lesion formation (Fig. 5). Meanwhile, the number of new lesions in each treated plot with 30 apple trees remained quite low (about 25 lesions) compared with that in nontreated plots (about 85 lesions), thus exhibiting a control efficacy of about $60 \%$ in 2011 to 2012. Similar results were obtained in June in 2012 to 2013 and 2013 to 2014, showing significant reduction in lesion formation and a stabilized control efficacy of about $55 \%$. Thus, $S$. yanglingensis Hhs.015 significantly reduced lesion formation and could be used as an effective preventive measure in control of AVC.

Healing effect of $S$. yanglingensis Hhs.015 on AVC lesions in orchards. The treatment with FB significantly improved the healing effect after 2, 6, 9, and 12 months (Table 2). The mean width of the callus from the treated trees 12 months after the treatment was $6.70 \mathrm{~mm}$ whereas that of the nontreated groups was just $1.97 \mathrm{~mm}$ (Table 2). In addition, the treatment also significantly improved the cure rate of postoperative lesions (76.2\%) as compared with the control $(38.1 \%)$. Also, similar results were obtained in 2011 and 2013, showing a significant healing effect after treatment with FB, exhibiting a cure rate of the postoperative lesions up to $80 \%$. Thus, the treatment with $S$. yanglingensis Hhs.015 accelerated wound healing and reduced the recurrence of the disease in the orchard.

Table 2. Effects of Saccharothrix yanglingensis Hhs.015 fermentation broth (FB) on callus formation of the wounds after lesion surgery

\begin{tabular}{|c|c|c|c|c|c|}
\hline \multirow[b]{2}{*}{ Time } & \multirow[b]{2}{*}{ Treatment $^{\mathrm{z}}$} & \multicolumn{4}{|c|}{ Callus width $(\mathrm{mm})^{\mathrm{y}}$} \\
\hline & & $2 \mathrm{mpt}$ & $6 \mathrm{mpt}$ & $9 \mathrm{mpt}$ & $12 \mathrm{mpt}$ \\
\hline \multirow[t]{2}{*}{2010} & Control & $1.02 \pm 0.12 b$ & $1.60 \pm 0.18 b$ & $1.90 \pm 0.15 b$ & $1.97 \pm 0.23 \mathrm{~b}$ \\
\hline & FB & $2.44 \pm 0.22 \mathrm{a}$ & $4.59 \pm 0.28 \mathrm{a}$ & $6.35 \pm 0.43 \mathrm{a}$ & $6.70 \pm 0.38 \mathrm{a}$ \\
\hline \multirow[t]{2}{*}{2011} & Control & $1.16 \pm 0.14 b$ & $1.73 \pm 0.13 b$ & $1.97 \pm 0.15 b$ & $2.05 \pm 0.20 \mathrm{~b}$ \\
\hline & FB & $2.43 \pm 0.17 \mathrm{a}$ & $4.76 \pm 0.23 \mathrm{a}$ & $6.54 \pm 0.25 \mathrm{a}$ & $6.81 \pm 0.28 \mathrm{a}$ \\
\hline
\end{tabular}

y Values are the mean \pm standard error of 21 replications and repeated three times; $\mathrm{mpt}=$ months posttreatment. Different lowercase letters in the same column in the same year indicate significant differences $(P=0.05)$ between the two treatments by a $t$ test.

${ }^{\mathrm{z}}$ The field trial was conducted in Pucheng County in April 2010 and repeated in April 2011. S. yanglingensis Hhs.015 FB and sterile water were used as the treatment and control, respectively. 


\section{Discussion}

In the present study, we focused on evaluating the potential of $S . y$ anglingensis strain Hhs.015 as a biocontrol against V. mali, and discovered that it suppressed AVC effectively in an orchard. Results in vitro, in controlled conditions, and in the field showed that Hhs. 015 significantly inhibited the growth and development of V. mali, and reduced new lesion formation, even enhancing callus formation in orchards.

Antagonism of strain Hhs.015 against V. mali was observed in the laboratory. These findings indicate that Hhs. 015 produces antifungal metabolites. It is commonly believed that endophytic actinomycetes control diseases by means of antibiosis (Furuya et al. 2011; Lin et al. 2014; Liu et al. 2010; Maurhofer et al. 1995; Wen et al. 2011). Hhs. 015 has been found to be effective against a wide range of fungal species (Gao et al. 2009; Yao et al. 2007). The results of this study are consistent with those of previous reports that Saccharothrix spp. exhibited a variety of antibiotic activities (Igarashi et al.1997; Kimura et al. 1995; Vértesy et al. 2001; Zitouni et al. 2004).

When the inhibition effect of $S$. yanglingensis strain Hhs.015 on lesion development of $V$. mali was tested on detached twigs, lesion development and pycnidial production were suppressed and delayed. These results indicate that Hhs.015 produces antifungal metabolites which suppressed growth and development of $V$. mali in the bark, reduced pycnidial production, and interrupted the disease cycle. These findings provided a basis for the further field experiments.

Wounds elicited by frost damage, sunscald, pruning, and other mechanical injuries are regarded as the main infection routes for $V$. mali (Adams et al. 2006; Kepley and Jacobi 2000). Especially in China, canker surgery, a practice commonly done by growers from early times (Wang et al. 1986), causes considerable wounding. Thus, protection is a key to preventing invasion. Our results showed that new lesion formation on trunks and branches smeared with FB of S. yanglingensis Hhs.015 was significantly reduced. These effects may be due to the ability of Hhs.015 to colonize tissues of trunks and branches and to secrete antibiotic substances directly to the targeted area, suppressing pathogen infection. Therefore, painting wounds with Hhs.015 could potentially provide sustained protection of apple trees from Valsa canker. Importantly, this strain is also effective in promoting callus formation on the wounds after the canker surgery, possibly due to production of some secondary metabolites that promote wound healing.

In summary, the present study showed that $S$. yanglingensis Hhs.015 exhibited robust preventive and therapeutic effects against AVC. To our knowledge, this is the first study to demonstrate that an actinomycete strain can inhibit AVC in orchards. Therefore, the strain may be useful as an effective alternative method for managing AVC. Our future research will be aimed at identifying the potential active substances produced by S. yanglingensis Hhs. 015 and developing a strategy for the practical application of this treatment in orchards for control of AVC on a large scale.

\section{Acknowledgments}

This research was supported by the National Natural Science Foundation of China (number 31101476 and number 31171796), Science and Technology Innovation Research of Shaanxi (number 2011KTZB02-02-02), Special Fund for Agro-scientific Research in the Public Interest of China (201203034), and the 111 Project (B07049). We thank M. L. Gleason at Iowa State University and $\mathrm{X}$. Chen at Washington State University for proofreading the manuscript.

\section{Literature Cited}

Abe, K., Kotoda, N., Kato, H., and Soejima, J. 2007. Resistance sources to Valsa canker (Valsa ceratosperma) in a germplasm collection of diverse Malus species. Plant Breed. 126:449-453.

Abe, K., Kotoda, N., Kato, H., and Soejima, J. I. 2010. Genetic studies on resistance to Valsa canker in apple: Genetic variance and breeding values estimated from intra- and inter-specific hybrid progeny populations. Tree Genet. Genomes 7:363-372.

Adams, G. C., Roux, J., and Wingfield, M. J. 2006. Cytospora species (Ascomycota, Diaporthales, Valsaceae): Introduced and native pathogens of trees in South Africa. Australas. Plant Pathol. 35:521-548.

Bessho, H., Soejima, J., and Tsuchiya, S. 1994. Screening methods of apple trees for resistance to Valsa canker. Prog. Temperate Fruit Breed. 1:49-52.

Chen, C., Li, M. N., Shi, X. Q., and Wang, J. Y. 1987. Studies on the infection period of Valsa mali Miyabe et Yamada, the causal agent of apple tree canker. Acta Phytopathol. Sin. 17:65-68.
Furuya, S., Mochizuki, M., Aoki, Y., Kobayashi, H., Takayanagi, T., Shimizu, M., and Suzuki, S. 2011. Isolation and characterization of Bacillus subtilis KS1 for the biocontrol of grapevine fungal diseases. Biocontrol Sci. Technol. 21:705-720.

Gao, Z. P., Ke, X. W., Wei, J. L., Chen, Y. C., Kang, Z. S., and Huang, L. L. 2009 Biocontrol efficacy of apple tree Valsa canker by endophytic actinomycetes. Acta Phytophylac. Sin. 36:410-416.

Huang, L. L., Kang, Z. S., Heppner, C., and Buchenauer, H. 2001. Ultrastructural and immunocytochemical studies on effects of the fungicide Mon65500 (Latitude ${ }^{\circledR}$ ) on colonization of roots of wheat seedlings by Gaeumannomyces graminis var. tritici. Z. Pflanzenkrankh. Pflanzenschutz 108:188-203.

Igarashi, M., Nakamura, H., Naganawa, H., and Takeuchi, T. 1997. Formamicin, a novel antifungal antibiotic produced by a strain of Saccharothrix sp. II. Structure elucidation of formamicin. J. Antibiot. 50:932-936.

Ke, X. W., Huang, L. L., Han, Q. M., Gao, X. N., and Kang, Z. S. 2013. Histological and cytological investigations of the infection and colonization of apple bark by Valsa mali var. mali. Australas. Plant Pathol. 42:85-93.

Kepley, J. B., and Jacobi, W. R. 2000. Pathogenicity of Cytospora fungi on six hardwood species. J. Arboric. 26:326-332.

Kimura, T., Nakamura, K., and Takahashi, E. 1995. Phosphonothrixin, a novel herbicidal antibiotic produced by Saccharothrix sp. ST-888. II. Structure determination. J. Antibiot. 48:1130-1133.

Lee, D.-H., Lee, S.-W., Choi, K.-H., Kim, D.-A., and Uhm, J.-Y. 2006. Survey on the occurrence of apple diseases in Korea from 1992 to 2000. Plant Pathol. J. 22: 375-380.

Li, Z. P., Gao, X. N., Du, Z. T., Hu, Y., Kang, Z. S., and Huang, L. L. 2013. Survey of apple Valsa canker in Weibei area of Shaanxi province. Acta Agric. BorealiOccidentalis Sin. 22:174-178.

Lin, Y., Du, D., Si, C., Zhao, Q., Li, Z., and Li, P. 2014. Potential biocontrol Bacillus sp. strains isolated by an improved method from vinegar waste compost exhibit antibiosis against fungal pathogens and promote growth of cucumbers. Biol. Control 71:7-15.

Liu, B., Huang, L. L., Buchenauer, H., and Kang, Z. S. 2010. Isolation and partial characterization of an antifungal protein from the endophytic Bacillus subtilis strain EDR4. Pestic. Biochem. Physiol. 98:305-311.

Liu, X. Y., Lü, S., Wang, Y., Wang, K., Li, T. H., Han, Z. H., and Zhang, X. Z. 2011. Evaluation of resistance of malus germplasms to apple canker (Valsa ceratosperma). J. Fruit Sci. 28:843-848.

Maurhofer, M., Keel, C., Haas, D., and Défago, G. 1995. Influence of plant species on disease suppression by Pseudomonas fluorescens strain CHAO with enhanced antibiotic production. Plant Pathol. 44:40-50.

Qin, S., Xing, K., Jiang, J. H., Xu, L. H., and Li, W. J. 2011. Biodiversity, bioactive natural products and biotechnological potential of plant-associated endophytic actinobacteria. Appl. Microbiol. Biotechnol. 89:457-473.

Ren, J. H., Li, H., Wang, Y. F., Ye, J. R., Yan, A. Q., and Wu, X. Q. 2013 Biocontrol potential of an endophytic Bacillus pumilus JK-SX001 against poplar canker. Biol. Control 67:421-430.

Vértesy, L., Barbone, F. P., Cashmen, E., Decker, H., Ehrlich, K., Jordan, B., Knauf, M., Schummer, D., Segeth, M. P., and Wink, J. 2001. Pluraflavins, potent antitumor antibiotics from Saccharothrix sp. DSM 12931. J. Antibiot. 54:718-729.

Wang, J. Y., Li, M. N., Shi, X. Q., and Chen, C. 1986. Control technology on the repeat of apple Valsa canker. China Fruits. 1:14-16.

Wang, L., Zang, R., Huang, L. L., Xie, F. Q., and Gao, X. N. 2005. The investigation of apple tree Valsa canker in Guanzhong region of Shaanxi province. J. Northwest A\&F Univ. 33:98-100.

Wang, X. L., Huang, L. L., Kang, Z. S., Buchenauer, H., and Gao, X. N. 2010. Optimization of the fermentation process of Actinomycete strain Hhs.015. J. Biomed. Biotechnol. Article ID 141876.

Wang, X. L., Wei, J. L., Huang, L. L., and Kang, Z. S. 2011. Re-evaluation of pathogens causing Valsa canker on apple in China. Mycologia 103:317-324.

Wang, X. L., Zang, R., Yin, Z. Y., Kang, Z. S., and Huang, L. L. 2014. Delimiting cryptic pathogen species causing apple Valsa canker with multilocus data. Ecol. Evol. 4:1369-1380.

Wei, J. L., Huang, L. L., Gao, Z. P., Ke, X. W., and Kang, Z. S. 2010. Laboratory evaluation methods of apple Valsa canker disease caused by Valsa ceratosperma sensu Kobayashi. Acta Phytopathol. Sin. 40:14-20.

Wen, C. Y., Wang, K. X., and Shen, S. S. 2011. Research Articles: Purification and Structural Analysis of surfactin produced by endophytic Bacillus subtilis EBS05 and its antagonistic activity against Rhizoctonia cerealis. Plant Pathol. J. 27: 342-348.

Yan, X., Huang, L. L., Tu, X., Gao, X. N., and Kang, Z. S. 2012. Saccharothrix yanglingensis sp. nov., an antagonistic endophytic actinomycete isolated from cucumber plant. Antonie Leeuwenhoek 101:141-146.

Yao, M., Tu, X., and Huan, G. 2007. Screening of antagonistic endophytic actinomycetes against tomato pathogens and biocontrol effect on tomato leaf mould. J. Northwest A\&F Univ. (Nat. Sci. Ed.) 35:147-150.

Zhang, J. X., Gu, Y. B., Chi, F. M., Ji, Z. R., Wu, J. Y., Dong, Q. L., and Zhou, Z. S. 2015. Bacillus amyloliquefaciens GB1 can effectively control apple Valsa canker. Biol. Control 88:1-7.

Zitouni, A., Boudjella, H., Mathieu, F., Sabaou, N., and Lebrihi, A. 2004. Mutactimycin PR, a new anthracycline antibiotic from Saccharothrix sp. SA 103. I. Taxonomy, fermentation, isolation and biological activities. J. Antibiot. 57:367-372. 